COMUNICAÇÃO CIENTÍFICA

\title{
MANCHA FOLIAR EM BARU (Dipteryx alata) CAUSADA POR Phoma multirostrata ${ }^{1}$
}

\author{
JOSÉ RIBAMAR NAZARENO DOS ANJOS², MARIA JOSÉ D'ÁVILACHARCHAR ${ }^{3}$, \\ SÉRGIO SARAIVANAZARENO DOS ANJOS ${ }^{4}$, NILTONTADEU VILELAJUNQUEIRA ${ }^{5}$, \\ MARILIA SANTOS SILVA 6
}

RESUMO - Phoma multirostrata foi isolado de mudas de baru com sintomas de lesões foliares marrons em condições naturais, no Distrito Federal, em 2004. Testes de patogenicidade e o subsequente reisolamento do fungo comprovaram os postulados de Koch. A ocorrência de mancha foliar de baru causada por $P$. multirostrata é relatada pela primeira vez no Brasil.

Termos para indexação: Phoma multirostrata, baru, patogenicidade.

\section{LEAF SPOT IN BARU (Dipteryx alata) CAUSED BY Phoma multirostrata}

ABSTRACT - The fungus Phoma multirostrata was isolated from infected baru plants with large leaf spot symptoms in Brasília, Brazil, in 2004. Pathogenicity tests under greenhouse conditions and subsequent reisolation of Phoma multirostrata from artificially inoculated baru seedlings fulfilled the Koch's postulates. Symptoms of leaf spot appeared four days after inoculation in $100 \%$ of the inoculated seedlings. The present report is the first on the occurrence of leaf spot of baru caused by Phoma multirostrata in Brazil. Index Terms: Phoma multirostrata, baru, pathogenicity.

O baru (Dipteryx alata Vog.), amplamente disseminado no Cerrado do Brasil Central, pertencente à família Fabaceae, é uma árvore frutífera, apresenta caule ereto e atinge até $15 \mathrm{~m}$ de altura. Sua madeira, de cor clara e pesada, com densidade de $1,10 \mathrm{~g} / \mathrm{cm}^{3}$ (Lorenzi, 1992; Almeida et al., 1998), presta-se para construção de estruturas externas, bem como para construções civil e naval. As sementes, fontes significativas de lipídios e de proteínas (Takemoto et al., 2001), são utilizadas na alimentação humana. Essa espécie tem grande potencial também para utilização paisagística e para recuperação de áreas degradadas (Lorenzi, 1992).

No Brasil, há relatos da ocorrência de tombamento seguido de morte de plantas de baru em viveiro, causado por Cylindrocladium clavatum Hodges \& May e por Fusarium oxysporum Schlecht (Santos, 1996). Santos et al. (1997) relataram a associação dos fungos Phomopsis sp., Lasiodiplodia theobromae (Pat.) Griffon,
Aspergillus niger P.E.L. van Tieghem, A. flavus Link Fr., Aspergillus spp., Fusarium sp. e Penicillium sp. com sementes de baru, sendo Phomopsis sp. o mais frequente. $\mathrm{O}$ presente trabalho teve como objetivos identificar e caracterizar um isolado de Phoma sp. causando mancha foliar em baru, em condições naturais, no Distrito Federal, e avaliar sua patogenicidade em plântulas dessa espécie.

Em 2004, foram observadas manchas foliares escuras e irregulares em mudas de baru (Figura 1-A) com aproximadamente um ano, em um viveiro aberto, no campo experimental da Embrapa Cerrados, Planaltina, Distrito Federal. O isolamento do agente etiológico foi efetuado a partir de tecido infectado, em meio de BDA + estreptomicina, e incubado sob luz branca constante $\mathrm{a} \pm 26{ }^{\circ} \mathrm{C}$. Culturas monospóricas de Phoma sp. foram enviadas para o CABI Bioscience, em Egham, Surrey, Reino Unido, para a identificação da espécie, além de usar-se a literatura especializada para a comparação das

${ }^{1}$ (Trabalho 172-08). Recebido em: 30-06-2008. Aceito para publicação em: 21-11-2008.

${ }^{2}$ Dr. Pesquisador da Embrapa Cerrados, BR 020 km 18, 73301-970, Planaltina-DF, e-mail: ribamar@cpac.embrapa.br.

${ }^{3}$.Dra. Pesquisadora da Embrapa Cerrados, E-mail mdavila@cpac.embrapa.br.

${ }^{4}$.BSc. Analaista da Embrapa Recursos Genéticos e Biotecnologia, Av. W3 Norte (final), 70770-900, Brasília-DF, E-mail: nazareno@cenargen.embrapa.br.

${ }^{5}$.Dr. Pesquisador da Embrapa Cerrados, E-mail: junqueir@cpac.embrapa.br.

${ }^{6}$.Dra. Pesquisadora da Embrapa Cerrados, E-mail: marilia@cpac.embrapa.br 
características morfológicas do isolado (Boerema et al., 2004; Aveskamp et al., 2008). A espécie foi identificada pelo Dr. P. F. Cannon como Phoma multirostrata (P.N. Mathur, S.K Menon \& Thirum) Dorenb. \& Boerema (IMI 393239). As colônias do fungo, nas condições da incubação, eram inicialmente brancas, com micélio abundante, tornando-se acinzentadas após 3-4 dias. O verso da colônia era de coloração acinzentada a escura. Os conídios eram hialinos, unicelulares, predominantemente elípticos e agutulados. Em 110 conídios medidos em uma lâmina semipermanente com lactofenol, as dimensões eram de 2,5 $\mu \mathrm{m}$ de largura e 2,5-6,25 $\mu \mathrm{m}$ de comprimento. Os picnídios eram escuros, globosos, a maioria solitários e com pescoço curto, variáveis em tamanho, medindo entre 65-162,5 $\mu \mathrm{m}$ de diâmetro. Os clamidósporos, comuns em culturas velhas (30 dias ou mais), eram frequentemente intercalados, mas às vezes terminais, de coloração marrom-escura, a maioria medindo entre 7,5-15 um de diâmetro.

$\mathrm{O}$ teste de patogenicidade foi efetuado em 20 mudas de baru com dois meses de idade, aderindose às folhas um disco de $5 \mathrm{~mm}$ de diâmetro de uma cultura monospórica do fungo, em BDA, após ferimento com agulha esterilizada. Após a inoculação, as mudas foram mantidas em uma câmara de incubação a $25^{\circ} \mathrm{C}$, durante $72 \mathrm{~h}$. Vinte mudas sadias, submetidas às mesmas condições, exceto a inoculação do fungo, serviram como testemunhas. Em seguida, as mudas foram transferidas para uma casa de vegetação. Os primeiros sintomas de mancha foliar foram observados em todas as plantas inoculadas, quatro dias após a inoculação (Figura 1-B). O reisolamento de $P$. multirostrata comprovou os postulados de Koch, confirmando-o como o agente causal da mancha foliar de baru.

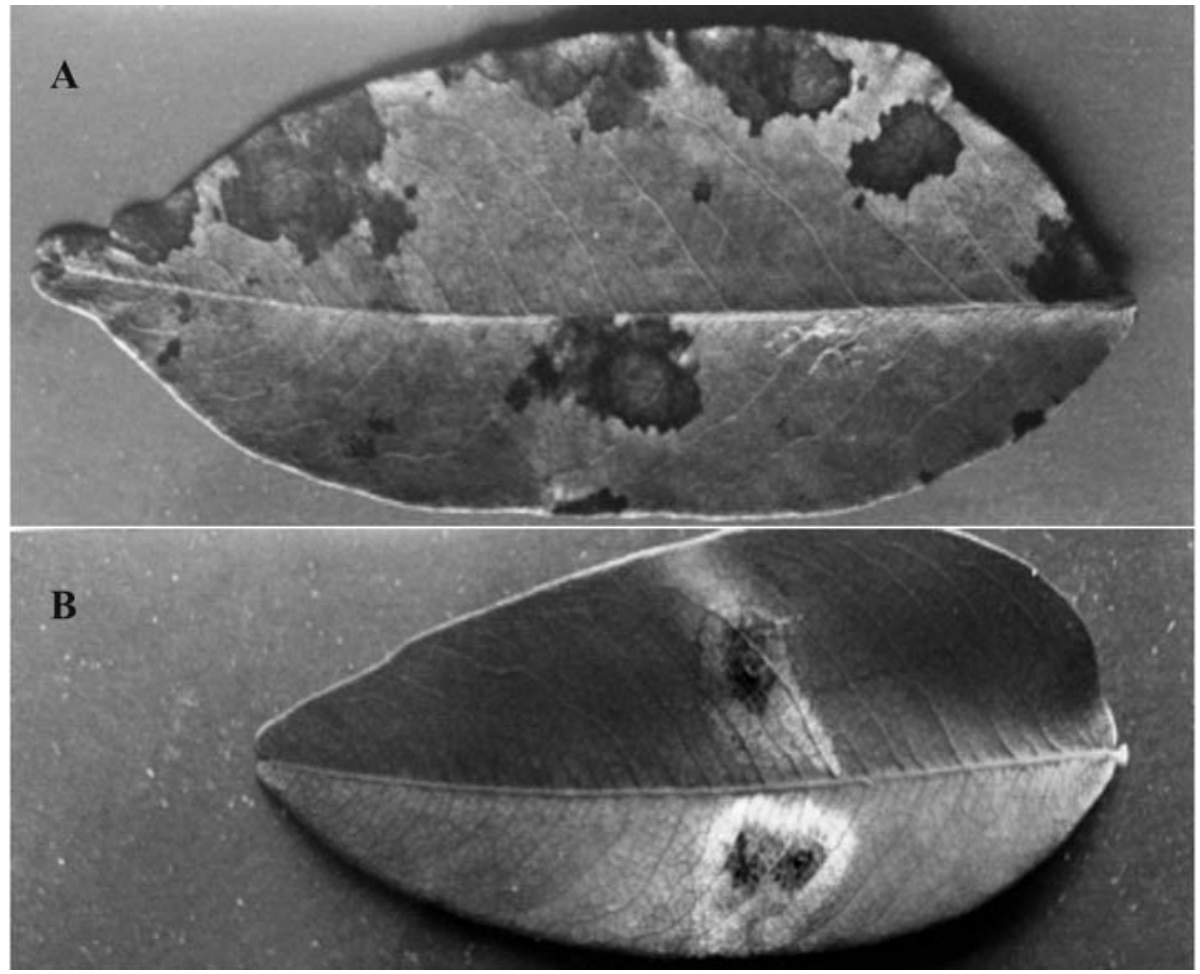

FIGURA 1 - Sintomas de mancha foliar em Dipteryx alata causados por Phoma multirostrata. A) Sintomas em condições naturais. B) Sintomas após inoculação artificial com $P$. multirostrata. 


\section{REFERÊNCIAS}

ALMEIDA, S.P.; PROENÇA, C.E.B.; SANO, S.M.; RIBEIRO, J.F. Cerrado: espécies vegetais úteis. Planaltina: Embrapa-CPAC, 1998. 464p.

AVESKAMP, M.M.;DE GRUYTER, J.; CROUS, P.W. Biology and recent developments in the systematics of Phoma, a complex genus of major quarantine significance. Fungal Diversity, China, v.31, p.1-18, 2008.

BOEREMA, G.H.; GRUYTER, J.; NOODERLOOS, M.E.; HAMERS, M.E. Phoma identification manual: differentiation of specific and intra-specific taxa in culture. Wallingford, UK: CABI Publishing, 2004. 470p.
LORENZI, H. Árvores brasileiras: manual de identificação e cultivo de plantas arbóreas nativas do Brasil. São Paulo: Ed. Plantarum, 1992. 368p.

SANTOS, M.F. Análises da microflora associada ao baru (Dipetryx alata Vog.) e à caroba [(Cybistax antisyphilitica (Mart.) Mart.]. 1996. $106 \mathrm{f}$. Dissertação (Mestrado) - Universidade de Brasília, Brasília, 1996.

SANTOS, M.F.; RIBEIRO, W.R.C.; FAIAD, MG.R.; SANO, S.M. Fungos associados às sementes de baru (Dipteryx alata Vog.). Revista Brasileira de Sementes, Pelotas, v.19, p.135-139, 1997.

TAKEMOTO, E.; OKADA, I.A.; GARBELOTTI, M.L.; TAVARES, M.; AUED-PIMENTEL, S. Composição química da semente e do óleo de baru (Dipteryx alata Vog.) nativo do Município de Pirenópolis, Estado de Goiás. Revisto do Instituto Adolfo Lutz, São Paulo, v.60, p.113-117, 2001. 